1 Newbold KM. Neutropenic enterocolitis. Clin Pathol Rev Dig Dis 1989;7:281-7.

2 King A, Rampling A, Wight DGD, Warren RE. Neutropenic enterocolitis due to Clostridium septicum infection 7 Clin Pathol 1984;37:335-43.

3 Speirs G, Warren RE, Rampling A. Clostridium tertium septicaemia in patients with neutropenia. I Infect Dis septicaemia in patient

4 Valtonen $M$, Sivonen A, Elonen E. A cluster of seven cases of Clostridium tertium septicaemia in neutropenic patients. Eur F Clin Microbiol Infect Dis 1990; 1:40-2.

5 Yates P, MacGowan AP, Potter M, White H, Slade RR. Clostridia and neutropenic enterocolitis. Lancet 1988; i: 185 .
6 Gabay EL, Rolfe RD, Finegold SM. Susceptibility , of Clostridium septicum to 23 antimicrobial agents. Antimicrob Agents Chemother 1981;20:852-3.

7 Masella T. A case of gas gangrene due to Bacillus tertius associated with Staphylococcus aureus. Riforma Med associated with

8 Lawrence G, Skerman F, Freestone DS, Walker PD. Prevention of necrotising enteritis in Papua New Guinea by active immunisation. Lancet 1979; i:227-9.

9 Slavin RE, Dias MA, Saral R. Cytosine arabinoside induced gastrointestinal toxic alterations in sequential chemotherapeutic protocols. Cancer 1978;42:1747-59.

10 Koea JB, Shaw JHF. Surgical management of neutropenic enterocolitis. Bn ₹ Surg 1989;76:821-4.

\title{
Mixed adenocarcinoma/carcinoid tumour of large bowel in a patient with Crohn's disease
}

\author{
Y L Hock, K W M Scott, R H Grace
}

Department of Y L Hock

K W M Scott

Department of

Surgery

R H Grace

The Royal Hospital, Cleveland Road, Wolverhampton WV2 1BT

Correspondence to: Dr YL Hock, Department of Histopathology, Dudley Road Hospital, Dudley Road, Birmingham B18 7QH

Accepted for publication 24 September 1992 Histopathology

\begin{abstract}
A 50 year old woman with a 20 year history of Crohn's disease underwent laparotomy which revealed extensive disease in the small and large bowel, and this was resected. Gross examination of the resected bowel showed features of Crohn's disease as well as a polypoid tumour in the caecum. Histopathological examination of the tumour showed it to be an infiltrating mixed adenocarcino$\mathrm{ma}$ carcinoid tumour arising in a tubulovillous adenoma.

Random sampling of the rest of the bowel affected by Crohn's disease also showed a focus of dysplasia and adeno-
\end{abstract}

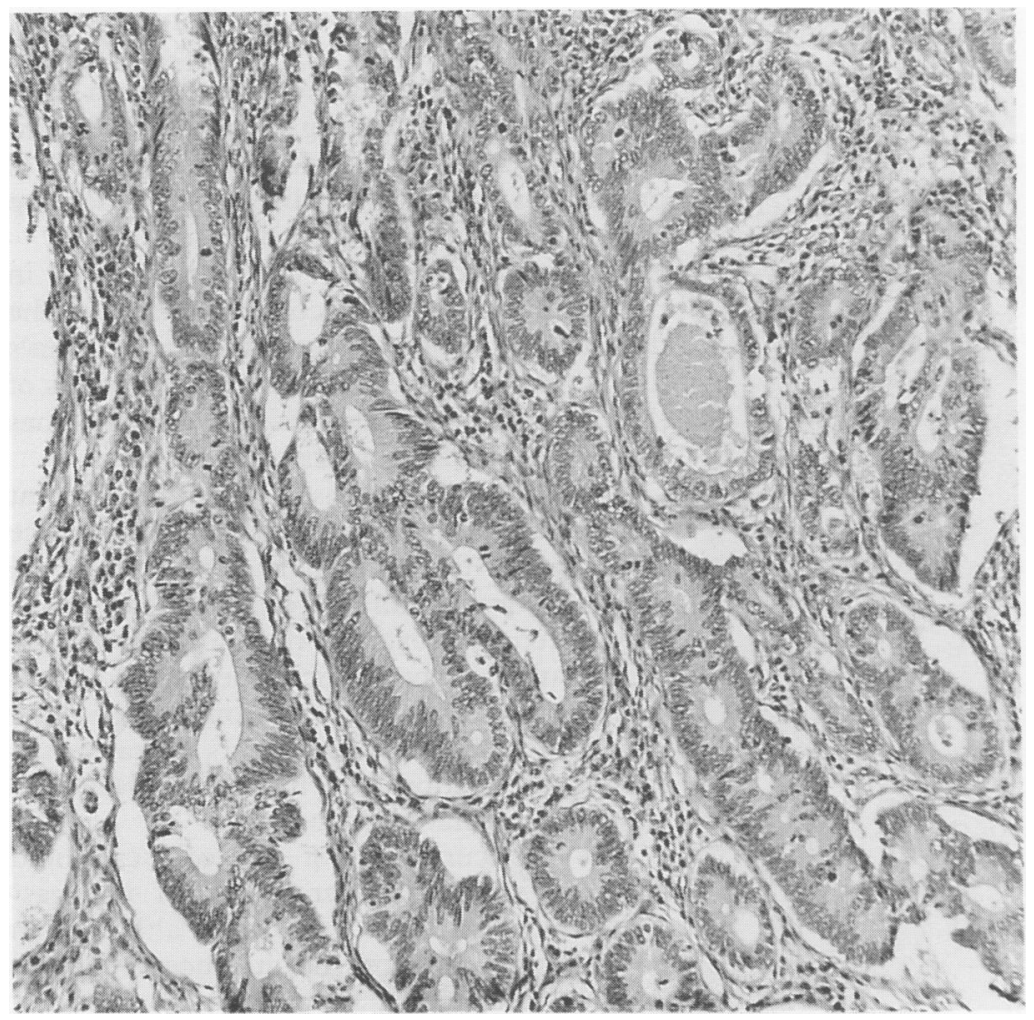

Figure 1 A focus showing typical features of moderately differentiated colonic adenocarcinoma (haematoxylin and eosin). matous change. It is suggested that Crohn's disease may have played a part in the pathogenesis of the tumour.

\section{(f Clin Pathol 1993;46:183-185)}

It has long been recognised that patients with ulcerative colitis may develop large bowel cancer $^{1}$; it has more recently also been recognised that in Crohn's disease there may be malignant change in association with both small and large bowel disease. ${ }^{2}$ Carcinoid tumours have been described both in ulcerative colitis ${ }^{3}$ and Crohn's disease. ${ }^{2}$ Mixed adenocarcinoma/carcinoid tumours have been described in ulcerative colitis ${ }^{1}$ but not in association with Crohn's disease.

\section{Case report}

A 50 year old woman with a 20 year history of small and large bowel Crohn's disease was admitted to hospital for laparotomy following the failure of medical treatment for increasingly severe right iliac fossa pain. There were no clinical features suggestive of a carcinoid syndrome and as there was no clinical suspicion, biochemical tests for carcinoid syndrome were not performed.

Laparotomy showed Crohn's disease from $15 \mathrm{~cm}$ proximal to the ileo-caecal valve to the junction of the descending and sigmoid colon. The region of the appendix was adherent to the anterior abdominal wall. Resection of the affected bowel with ileo-sigmoid anastomosis was performed.

\section{Pathological examination}

The specimen included $15 \mathrm{~cm}$ of terminal ileum and $45 \mathrm{~cm}$ of large bowel. A paracaecal abscess encasing the appendix was noted. On opening the bowel, there was a continuous segment of mucosa showing the typical "cobble stone" appearance of Crohn's disease, measuring $32 \mathrm{~cm}$ in length and involving the 


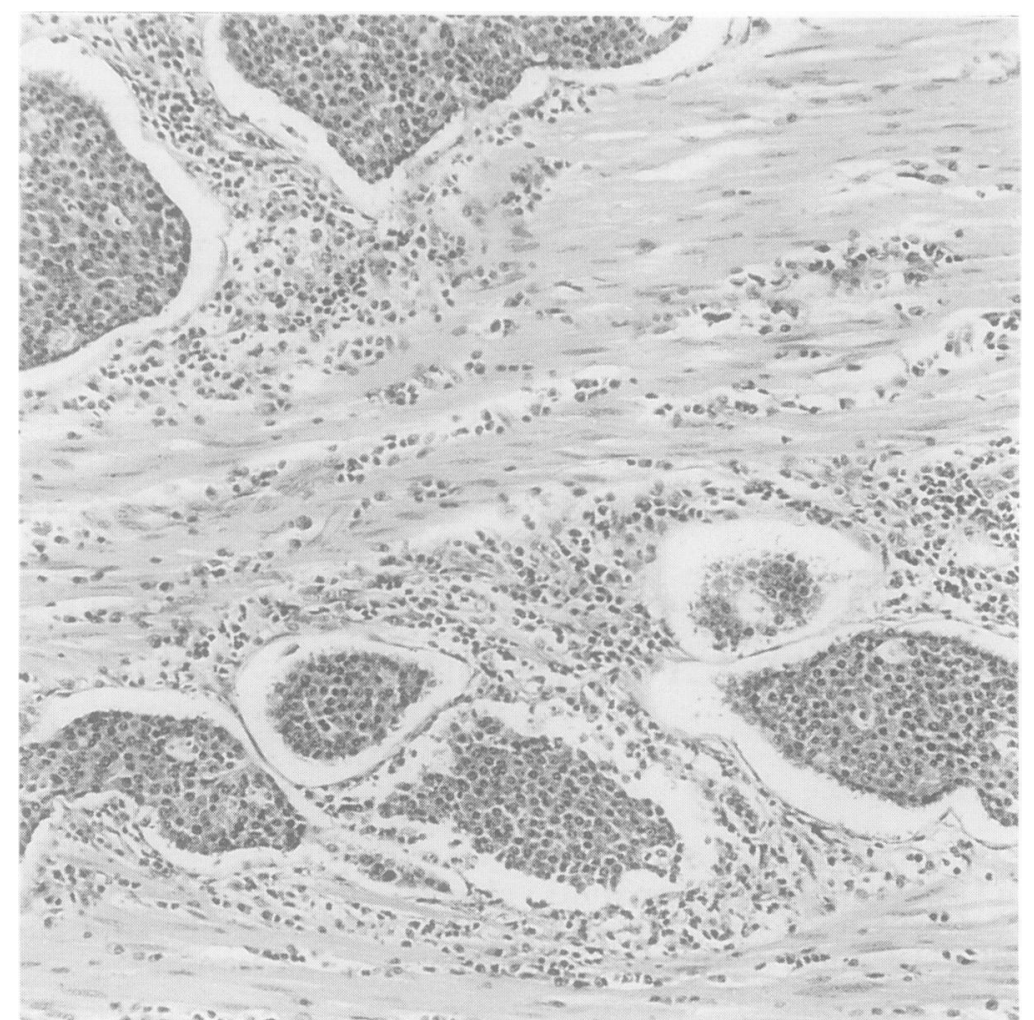

Figure 2 Another focus shows solid nests of uniform cells surrounded by peripheral rims of smaller cells with hyperchromatic nuclei typical of carcinoid tumour (haematoxylin and eosin).

terminal ileum and the adjacent colon.

A polypoid lesion, $3 \mathrm{~cm}$ in diameter, was noted in the caecum with the adjacent $3 \mathrm{~cm}$ of bowel mucosa appearing much thicker, firmer, and yellower than the surrounding
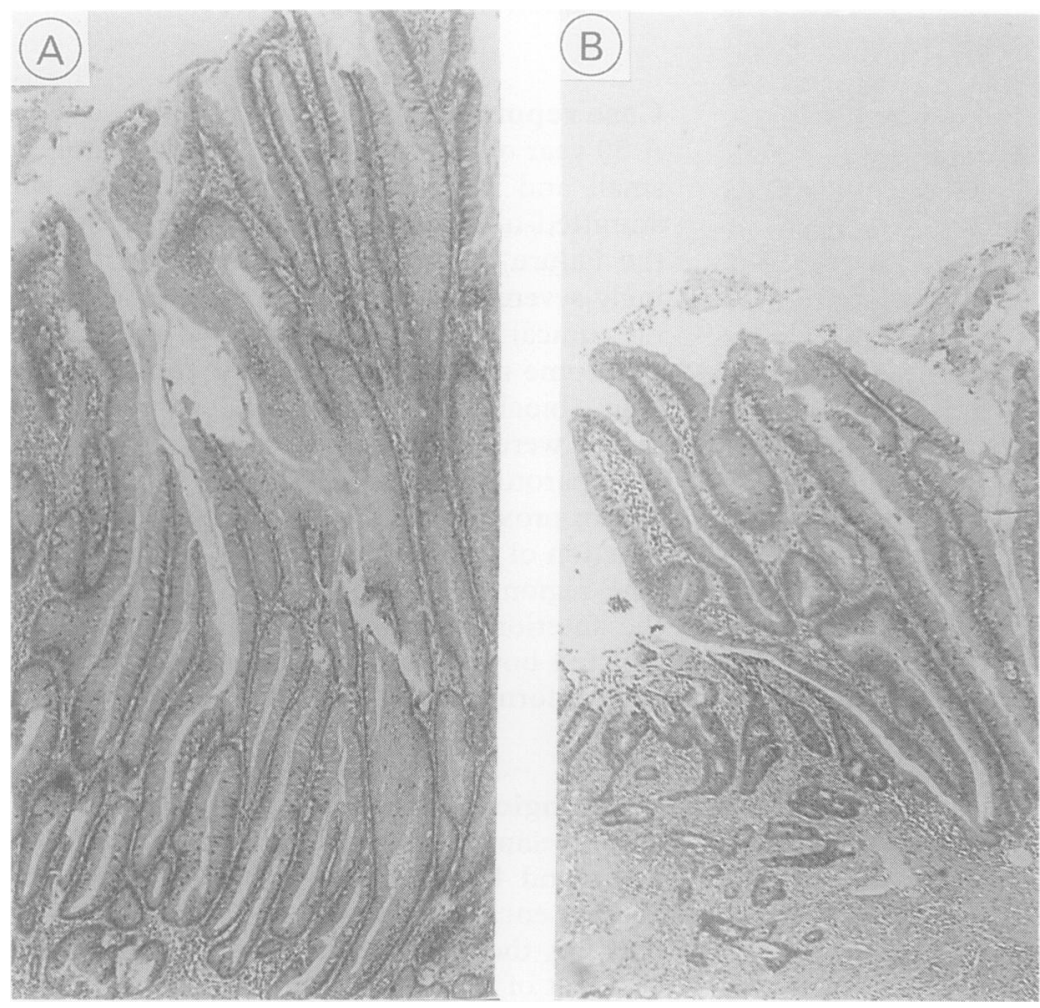

Figure 3 Villous adenomatous change showing epithelial dysplasia in: $(A)$ mucosa further away from the malignant tumour; $(B)$ the adjacent mucosa. The infiltrating tumour is also apparent in the left hand corner (haematoxylin and eosin). mucosa. Histological analysis showed the polypoid lesion to be a tubulovillous adenomatous polyp, which showed progressive dysplasia and became continuous with an area of infiltrating malignant tumour composed of an intimate admixture of two components: one component showing features of moderately differentiated colonic adenocarcinoma (fig 1), and the other showing solid nests and trabeculae of uniform cells, surrounded by peripheral rims of smaller cells with hyperchromatic nuclei (fig 2), typical of carcinoid tumour.

Occasional rosette formations were also seen. The foci of carcinoid areas showed negative diazo and Grimelius reactions, but strong positivity with neurone specific enolase on immunocytochemistry. The tumour had infiltrated through the full thickness of the bowel wall and into the pericolic fat.

Sections from the rest of the large bowel, as well as from the ileum, showed transmural chronic inflammation with numerous lymphoid aggregates. Giant cell granuloma were also seen in the muscularis propria and in the submucosa.

About $12 \mathrm{~cm}$ distal to the malignant tumour, the inflamed colonic mucosa also showed a separate small focus of villous adenomatous change with low grade epithelial dysplasia (fig 3A). There were no metastases or granulomata in the lymph nodes recovered.

The pathological diagnosis was mixed adenocarcinoma/carcinoid tumour (composite carcinoma carcinoid tumour) occurring in a colon affected by Crohn's disease.

\section{Discussion}

There is an accepted association between Crohn's disease and cancer of the gastrointestinal tract, and the relative risk compared with the normal population ranges from fourfold to 20 -fold according to various epidemiological studies. ${ }^{4}$ In real terms, roughly $2 \%$ of patients with Crohn's disease will develop cancer in the course of the disease.

Although the risk of colorectal cancer in patients with ulcerative colitis is related to the duration of disease, patients with Crohn's disease are at risk even in the first 10 years of their disease, ${ }^{2}$ and the disease activity does not appear to affect the risk of cancer.

It has been established that malignant change in Crohn's disease is often a chance discovery by the pathologist, and $59 \%$ of all cancers complicating Crohn's disease have only been discovered during pathological examination of the surgical specimens. ${ }^{5}$ As in ulcerative colitis, adenocarcinoma of the large bowel in Crohn's disease occurs characteristically in association with foci of dysplasia and villous adenomatous change. ${ }^{6}$

The concurrence of typical carcinoid admixed with adenocarcinoma of the gastrointestinal tract is a well known although an unusual phenomenon that has been reported in the oesophagus, stomach, gall bladder, colon and appendix, and has been termed composite carcinoma carcinoid tumour. ${ }^{7}$ 
Although the occurrence of such a tumour has been reported in association with ulcerative colitis, ${ }^{1}$ no such colonic tumour has been reported in association with Crohn's disease. In this case a composite carcinoma carcinoid tumour was found in the caecum affected by active Crohn's disease, and a focus of dysplasia and villous adenomatous change was seen in adjacent mucosa as well as in mucosa further away from the tumour (fig 3).

The occurrence of composite carcinoma carcinoid tumour in the colon can be readily explained by the tumour arising from the multipotent stem cells showing bidirectional differentiation, ${ }^{7}$ and the presence of a tubulovillous adenoma showing progressive dysplasia, finally becoming an infiltrating tumour in our case, is entirely in agreement with this view. However, why the tumour differentiated bidirectionally as such and whether Crohn's disease played any particu- lar role is not known.

We are grateful to Drs MG Freeth and C Allen for helpfu comments, Dr SY Chan for help with photomicrographs, and Mrs Sue Clarke for typing the manuscript.

1 Lyss AP, Thompson JJ, Glick JH. Adenocarcinoid tumour of the colon arising in pre-existing ulcerative colitis. Cancer 1981;48:833-9.

2 Saroca PE, Ballantyne GA, Cahow CE. Gastrointestina malignancies in Crohn's disease, a 20 year experience. Dis Colon Rectum 1990;33:7-11.

3 Gledhill A, Hall PA, Cruse JP, Pollock DJ Enteroendocrine cell hyperplasia, carcinoid tumours and adenocarcinoma in long-standing ulcerative colitis. Histopathology 1986; 10:501-8.

4 Hamilton SR. Colorectal carcinoma in patients with Crohn's disease. Gastroenterology 1985; 89:398-407.

5 Thompson EM, Clayden G, Price AB. Cancer in Crohn's disease- an 'occult' malignancy. Histopathology 1983; 7:365-76.

6 Craft CF, Mendelsohn G, Cooper HS, Yardley JH. Colonic 'precancer' in Crohn's disease. Gastroenterology 1981; 80:578-84.

7 Klappenbach RS, Kurman RJ, Sinclair CF, James LP. Composite carcinoma/carcinoid tumours of the gastrointestinal tract. Am f Clin Pathol 1985; 84:137-43.

\title{
Epithelial myoepithelial tumour of the tracheal gland
}

\author{
H Horinouchi, T Ishihara, M Kawamura, R Kato, K Kikuchi, K Kobayashi, Y Maenaka, \\ C Torikata
}

\begin{abstract}
A case of epithelial myoepithelial tumour originating from the tracheal gland in a 57 year old woman is described. The tumour was removed by segmental tracheal resection and end-to-end anastomosis. Histologically, the tumour comprised clear cells and presented a monophasic pattern. Immunohistochemical analysis showed that the tumour cells were positive for both S-100 protein and smooth muscle actin, suggesting that this tumour resembles a subtype of epithelial-myoepithelial carcinoma described in the 1990 WHO international classification of salivary glands.

Although some reports describe a clear cell dominant epithelial myoepithelial carcinoma, in this case local invasiveness or regional lymphnode metastasis was not proved through investigation. It is therefore concluded that this was an epithelial myoepithelial tumour rather than a carcinoma.
\end{abstract}

$(\Im$ Clin Pathol 1993;46:185-187)

Among the cases difficult to classify histologically, the rare case presented here, that of a tracheal tumour, is thought to be a clear cell dominant epithelial myoepithelial tumour.
In 1972 Donath and coworkers reported a special form of a clear cell tumour of the salivary gland, which they termed epithelial myoepithelial carcinoma of the intercalated ducts. ${ }^{1}$ This type of tumour had been previously described as clear cell monomorphic adenoma in the WHO classification ${ }^{2}$ and the AFIP Tumor Fascicle. ${ }^{3}$

\section{Case Report}

A 57 year old Japanese woman was admitted in August 1988 because she was producing bloody sputum. She had been treated for bronchiectasis and diabetes mellitus by her family doctor since November 1985. A harsh, stenotic sound was audible on her neck. There was no cervical lymphadenopathy. The chest $X$ ray film revealed a large intraluminal defect in the cervical trachea (fig 1). A computed tomogram of the trachea indicated a clearly demarcated mass in the mid-trachea. Bronchofibroscopy showed the presence of polypoid tumour growing from the right side of the tracheal wall.

Surgery was performed in August 1988. The trachea was mobilised from the neck to the carina, sleeve resection comprising five tracheal rings (third to seventh tracheal cartilages) was performed, and an end-to-end anastomosis was accomplished. Additional regional lymph node dissection was done. A tiny, hard thyroid nodule in the right lower pole of the thyroid was found. This was also 